\title{
Everything About Kangaroos
}

\author{
KANGAROOS, $2^{\text {nd }}$ EDITION. By T. J. Dawson. Collingwood, Australia: CSIRO \\ Publishing, Australian Natural History Series. 2012. 216 pp., AU \$ 39.95 (paperback). \\ ISBN: 9780643106253.
}

\section{Marilyn B. Renfree}

This new, second edition of Terry Dawson's Kangaroos (Australian Natural History Series; originally from University of New South Wales Press) is a splendid update from the world expert on kangaroo ecology and biology. The easy writing style makes this volume accessible to readers who have a general interest in kangaroos, as well as providing a wealth of detailed information for the kangaroo biologist. Dawson's book covers population structure, reproductive biology, life history, feeding, environmental physiology and finally their interactions with humans, both indigenous and recent. His knowledge of these animals comes from 45 years of study.

Terry begins with a history of kangaroo discovery and a definition of these iconic marsupials. With over 70 species, the kangaroo family is large indeed, but this volume focuses on the large kangaroos and euros (the latter a widespread subspecies of wallaroo, Macropus robustus). In particular, the Fowlers Gap animals - the Red kangaroo, the Eastern grey kangaroo, the Western grey kangaroo, and the Euro are the stars of this book. In the semi-arid environment in which these animals live, it must be an advantage to have such an efficient mode of locomotion. At high speeds, kangaroos experience lower energy costs than a comparably-sized quadruped. That hopping can be sustained at $20 \mathrm{~km} / \mathrm{hr}$ over long distances, with rapid bursts of up to $45 \mathrm{~km} / \mathrm{hr}$, is quite amazing enough, but the top recorded 
speeds of $55-60 \mathrm{~km} / \mathrm{hr}$ are nothing short of astonishing. It is hardly surprising then, that $86 \%$ of the total volume of mitochondria in the Red kangaroo body is found in the upper hind leg and pelvis!

Kangaroos are abundant in Australia. Farmlands, especially through the additional availability of water, have increased their numbers, and kangaroos can move to other locations in response to climate changes. Because of their mobility, surveys can often underestimate or overestimate populations, and some of the best studies were conducted by Dawson and colleagues at Fowlers Gap where they measured age structure, sex ratio, body weight, behavior, dispersal, and mortality. In good conditions in southern New South Wales, $85 \%$ of Red kangaroo young that exited their mother's pouches survived to weaning, but in drought-affected southern Queensland, survival was only 17\%. Dingoes are the primary predators of kangaroos (that is, apart from humans and the annual kangaroo harvest, which is tightly regulated and monitored). Foxes do take juvenile kangaroos but seem to have little effect on kangaroo populations as a whole.

Kangaroos live in mobs whose home ranges overlap, and have a well-established social structure. Group sizes vary quite a lot, and there are dominance hierarchies among both males and females. Antilopine kangaroos are the most social, followed by the Eastern grey kangaroo. Red kangaroos and Euros, who are continuous breeders, have small group sizes. Grey kangaroos are seasonal breeders, and all kangaroos except the Western grey use embryonic diapause as a reproductive strategy, which enhances their reproductive success. As everyone knows, the kangaroo has a well-developed pouch in which the young completes most of its development. Pregnancy lasts only around one month, which contrasts with the long (and physiologically sophisticated) lactation period that ranges from 360 to 540 days. The young spend the first 235 days (Red kangaroo) to 320 days (Eastern grey) confined in the pouch before they first exit. At permanent pouch exit, the young Red kangaroo weighs about 
$20 \%$ of its mother's body weight! Young remain associated with their mothers for some time after permanent pouch exit. The age of sexual maturity varies somewhat with environmental conditions, with Red kangaroos typically reaching puberty at around 15-20 months, but in drought this may be delayed to as late as four years.

Kangaroos are foregut fermenters, and depend on gut microorganisms, especially bacteria, to ferment their often dry and fibrous food. Kangaroos are also able to use nonprotein nitrogen compounds, e.g., urea, as an energy source. There is molar progression of the teeth in kangaroos, so that as teeth wear they move forward and are shed from the jaw. They are exquisitely adapted to the often arid environments they find themselves in, and this extends to their capability to withstand limited water access. Amazingly, Red kangaroos seldom drink in the cooler months, and only half returned to an observed water source within 12 days (the number for euros is one third). Dawson concludes that the relatively low water use by kangaroos is in part due to the lower metabolic rate of marsupials compared to eutherian mammals, and details their many adaptations to minimize water loss.

The final chapters discuss the relationship of kangaroos with humans. On the debate about the cause of the extinctions of Australia's megafauna, Dawson concludes that this did coincide with the arrivals of Aboriginal peoples on the continent and that they almost certainly contributed to it - but he also notes that it coincided with the increasing aridity that developed from that time. Since the arrival of settlers from Europe, kangaroos have been both loved and threatened, along with too many other mammals from this continent.

Throughout the book Terry Dawson provides the reader with a real 'feel' for what is involved in extensive field studies, most conducted in arid zone conditions, and he generously acknowledges the many researchers who have spent long hours in the field observing kangaroos (as well as those in the laboratory, although there is less emphasis on 
laboratory studies in this book). The book has a high standard of editing, with essentially no typographical errors apart from the misspelling of the word 'flehmen.' The extensive use of clear diagrams, photographs, and illustrations, accompanied by beautiful line drawings by the two artists, Anne Musser and Jillian Hallam, make this book a valuable addition to any serious kangaroo-ologists book shelf. Students will find it valuable, and it will appeal to a wide range of readers who want to know more about these marvellous marsupials. I thoroughly recommend it.

M. B. Renfree

Department of Zoology,

The University of Melbourne,

Victoria 3010, Australia

email: $\underline{\text { m.renfree@unimelb.edu.au }}$ 


\section{University Library}

\section{- M M I N E R VA A gateway to Melbourne's research publications}

Minerva Access is the Institutional Repository of The University of Melbourne

Author/s:

Renfree, MB

Title:

Everything About Kangaroos

Date:

2014-09

Citation:

Renfree, M. B. (2014). Everything About Kangaroos. Journal of Mammalian Evolution, 21 (3), pp.357-358. https://doi.org/10.1007/s10914-014-9258-5.

Persistent Link:

http://hdl.handle.net/11343/283067 